Interdisciplinary Product Design Education

by

Steven D. Eppinger

Charles $\mathrm{H}$. Fine

Karl T. Ulrich

WP \#3013-89-MS

May 1989 


\title{
Interdisciplinary Product Design Education
}

\author{
Steven D. Eppinger \\ Charles H. Fine \\ Karl T. Ulrich \\ Massachusetts Institute of Technology
Sloan School of Management
Cambridge, MA 02139 USA
}

\begin{abstract}
:
The demands of product design have changed. Development teams are expected to create superior products faster than ever. Educational programs must respond to this need by training design professionals who can develop world-class products. This article presents an approach to experiential education which has succeeded at MIT in motivating both engineering and management students to orient their academic studies and career plans towards design. Our course emphasizes that product development is an interdisciplinary function requiring skills that span departmental boundaries.
\end{abstract}

\section{Introduction and Background}

The world of product design and development has become more and more competitive, and the traditional university approach to engineering and management education must be upgraded to prepare design professionals to make rapid and significant contributions in this new environment. In this paper, we consider the demands of modern design practice in order to specify a model for educating design professionals. In the introduction we describe the motivation for a new way of teaching design, and outline some of the difficulties in meeting this challenge. The remainder of the paper describes a course that we teach at MIT which addresses some of the issues we raise. 


\section{The Changing World of Product Design and Development}

The world of product design is becoming more competitive. Currently, U.S. automobile manufacturers design new vehicles with an average lead time of 62 months, while the lead time for Japanese firms is only 43 months [Clark, et al 1987]. In 1978, tabletop copiers had manufacturing costs of $\$ 1500$. Today, copiers with similar performance characteristics can be made for $\$ 200$ [Jacobson and Hillkirk 1986]. In contrast to a decade ago, customers now expect television sets that never require adjustment or repair over a 10 year lifetime. These differences are not only the result of new technology and movement along the product lifecycle, but are also the result of improved design and manufacturing practices by a set of world-class firms. Several companies have recognized the importance of interdisciplinary skills and cross-functional teams [Barr 1989]. As educators, our responsibility is to train design professionals that can participate in and lead these product development teams. As researchers, our goal is to understand the sources of differences in design speed and quality among different firms, and to provide tools and insight for further improvement.

\section{Educational Needs}

The attributes of design professionals that make them valuable participants in product development teams - interdisciplinary skills in engineering and management, the ability to work effectively with team members, and the ability to generate novel ideas - are usually acquired only incidentally in university programs in engineering and management. This is primarily because the traditional engineering and management curricula are not structured to develop these attributes. Our challenges as university faculty involved in design education are: 1) to attract, excite, and motivate the very best students to pursue careers in design; 2) to educate design professionals that understand both the human and technical dimensions of product development; and 3) to teach fundamental material from several relevant, but diverse, disciplines.

Universities are organized into schools and departments. These departmental boundaries usually define a shared methodological approach to problem solving in a particular domain - mechanical engineers solve problems involving the transfer of materials, forces, and energy using the tools of engineering science; computer scientists solve information processing problems 
using the tools of mathematics; and behavioral scientists investigate questions of human interaction using the tools of psychology and sociology. This decomposition is an effective way to build a community of people that share common interests, and it provides a convenient organizational scheme for educating students. Unfortunately, just as functional organization schemes in industry make product development difficult [Allen 1977], the departmental framework in academia makes design education difficult.

The activity of designing products requires basic skills in marketing, engineering analysis, process technology, manufacturing management, organizational behavior, and industrial design. These skills must be augmented by an ability to synthesize and organize. In order to properly educate design professionals who will create world-class products, faculty from diverse disciplines must work together in ways that are unfamiliar within the organization of the university.

Based on an informal survey of ten leading mechanical engineering departments in the country ${ }^{1}$, only three have graduate courses that are intended to prepare students to develop new products. Most existing design courses in United States mechanical engineering departments focus on the design of capital equipment and the use of machine elements, but rarely deal with the design of high-volume discrete goods like consumer appliances and automobiles ${ }^{2}$. Several top management schools in the United States offer courses in product development; but they have an almost exclusive marketing focus without treating the technological dimensions of product design and manufacturing. Boston University, a notable exception, offers a course on product design and operations strategy.

\section{History of MIT Engineering SchoolManagement School Design Course}

We are familiar with efforts by faculty at other universities to address some of the concerns we have expressed. Although there may be others, we know of interdisciplinary design courses at Stanford University and the University of Michigan, in addition to a few existing courses at MIT. Knowledge of these programs was useful to us in defining our interdisciplinary design course.

1 The first ten departments as specified by the 1983 . National Academy of Sciences surveys.

2 This lack, and the need for change, are also articulated in [Rabins 1986]. 
In 1984 one of us (Fine) from the MIT Sloan School of Management collaborated with Professor Warren Seering of the MIT Department of Mechanical Engineering to coordinate joint design projects between the schools of management and engineering. As a result, six management students began product redesign Master's theses in 1984, that were augmented by the engineering efforts of mechanical engineering graduate students as part of a sixweek module in Seering's advanced engineering design projects course. During this six-week period, graduate students in engineering and management worked together to address problems provided from industry. This format was continued the next time Seering's course was taught, in 1987. In the spirit of these initial efforts, in 1988 we created a new course.

\section{Our Approach}

During the 1988-1989 academic year, we offered a course entitled Design for Manufacturability. Our collective experience is in economic models of manufacturing, technology and quality improvement, manufacturing strategy, manufacturing automation, computer-aided design, and design theory. We were interested in combining our different educational and research perspectives to meet an educational need. In order to gather an interdisciplinary group of students, we recruited from the second-year class of the Sloan Master's program and from the senior class in the Department of Mechanical Engineering. In the fall term, we scheduled lectures and workshops for the students, we grouped students into teams, and we matched student teams with product redesign projects at local companies. Although there were no formal class meetings in the spring, the students continued to meet in their project groups, with their industrial sponsors, and with the faculty member supervising their project. The project teams delivered final reports and, in some cases, engineering drawings and hardware, to their sponsors. Each student wrote a Bachelor's or Master's thesis, which was submitted at the end of the spring semester.

This course required significant amounts of organizational effort, primarily because we drew upon varied resources to achieve comprehensive coverage of the areas we consider relevant to design. In addition to our own lectures on topics such as fabrication techniques, engineering materials, and cost 
accounting, eight guest lecturers gave presentations on subjects such as teamwork and team building, consulting skills, and design theory and methodology. Only about half of the class meetings were used for lectures. The remaining sessions were conducted in laboratory or workshop mode, where students worked in teams on their projects or on "hardware exercises" used to illustrate certain design concepts.

We divided our class into four student teams, each with one or two management students and three engineering students. For each student, his/her portion of the project formed the basis for the (Master's or Bachelor's) thesis required for graduation. In previous years, management students used this project for the thesis, while engineering students received only course credit. This format was problematic because teams had members who differed widely on the amount of effort they were willing to contribute. With this year's requirement that all participating students use the course project for their thesis, students were highly motivated and willing to invest significant time in the work.

Each project involved the redesign of an existing product, rather than a clean-sheet design of a new product. Experience suggests that the latter causes students to focus primarily on concept generation and proof, excluding the important marketing and manufacturing issues. Redesign provides ample technical challenges and opportunities while pushing students to keep the business issues in the foreground.

We matched each of the student groups to a local industrial sponsor which provided the specific product to be redesigned. The student teams acted as design consultants to their sponsors, who in turn agreed to make data and personnel available to the students. As initially presented to the students, the projects were outlined only in broad terms; the student teams defined clearly the problems on which they would work, as well as the components to be tackled by each team member. In approaching their problems, the student teams first conducted background research into the clients' markets and products. They were then asked to write problem statements that identified their sponsors' needs and motivations for redesign. Once specific problems were defined, we challenged the teams to find ways they could contribute to the ongoing efforts of these companies. After participating in these steps, the students were well positioned to propose 
thesis topics. Each team identified individual thesis projects that collectively met the team's common goals.

\section{Design Project Examples}

In this section, we illustrate the scope of the student experiences. We describe each of the products that were redesigned in the class, and list some of the individual thesis projects.

\section{Medical Equipment Cart}

A local instrument manufacturer produces complex equipment used for medical diagnosis. One component of their system is the cart that carries the instrumentation through a hospital or clinic. The manufacturer originally designed the cart early in the development of the instrument system. Since then, the cart design has evolved to meet the changing requirements of the medical equipment system, but has never been carefully evaluated for cost. (The company has placed a great deal of engineering effort on the development of the instrumentation, but not on the development of the cart on which it rides.) The student team was asked to reduce the manufacturing cost of the cart by $25 \%$.

Some Thesis Projects:

- Combine similar components in the design to reduce the number of different parts required for the assembly.

- Investigate the use of alternative fastening technologies to eliminate some parts and reduce assembly time.

- Redesign the product to reduce the materials cost.

\section{Industrial Camera}

A manufacturer of photographic equipment markets an industrial camera as a component for OEMs to build into larger products. This sponsor was preparing to offer an improved product at the time of their patent expiration, to discourage foreign competition. The client company had a group of engineers working to redesign this product, and was very interested to see what ideas a group of MIT students could contribute. 
Some Thesis Projects:

- Design a new electrical switch and timer for improved reliability of the product.

- Calculate (estimate) the cost of poor quality to the consumer and to the manufacturer.

- Evaluate the client's use of "design" as a strategic competitive tool.

\section{Pressure Relief Valves}

A local valve company offers an extensive selection of pressure-relief valves; however, it feels that its market position would be stronger if it could offer a more limited selection of better-performing valves. The smaller product line would allow the production of larger quantities of each valve. The students worked to improve the product performance by combining the best characteristics of many valves into one superior design.

Some Thesis Projects:

- Develop a fluid flow model to predict certain aspects of valve performance.

- Combine the best features of two different designs into one new design.

- Develop a mathematical model which will show the relationships between design parameters and product performance.

\section{Baby Toy}

A baby products manufacturer has safety and cost as its greatest concerns. One of their best-selling infant products is a soft plastic, water-filled toy with floating trinkets inside. The students were asked to redesign the toy to alleviate the false consumer perception that the small objects may come out of the toy.

Some Thesis Projects:

- Develop a new manufacturing process technology that eliminates seams in a molded assembly.

- Analyze the firm's marketing strategy and pricing policy.

- Design and build a machine to test finished products for a particularly important aspect of quality. 


\section{Discussion}

The amount of time required by a company to bring a product from concept to market is a key correlate of industrial success. Success in the time-to-market domain seems to require effective teamwork both within and among the management and engineering ranks. The principal educational goal of our course is to teach management and engineering students how to work in teams and how bring to bear their different educations and experiences to efficiently reduce the time-to-market cycle. We consider our experience with this course a success in interdisciplinary and experiential design education. This success can be attributed to 1) the scope and duration of the projects, 2) the industrial orientation of the course, 3 ) the emphasis on problem definition, and 4) the focus on existing products. In this section we discuss each of these factors as well as a faculty research issue. The appendix offers advice to faculty who might be planning this type of course.

The course spans nine months and engages the students in activities from cost accounting to detailed mechanical design. The duration is long enough for the groups to develop important teamwork experience and for them to grope with the organizational and information gathering aspects inherent in large projects. The tasks that the students engage in are diverse enough that the students can test the bounds on their own skills and learn how to rely on team members with complementary skills.

This project course gives students a hands-on, real-world experience with which to evaluate and develop the tools and concepts they learn in other courses. Working on product design in the context of a complex, real-time, human environment provides students an opportunity to experiment with design work at no risk to their employment status. Learning from errors, misjudgments, and experience on the class projects will reduce problems (and anxiety) for these students in their first jobs, where the high risks of failure encourage more conservative problem solving strategies. The university is the last chance for students to test the limits of their problem solving skills in a stimulating but relatively benign environment.

Students spend a great deal of time researching the client, defining the whole problem, and then breaking down the project into individual thesis 
proposals. This forces students to consider their work as it fits into the larger efforts of their team and sponsor. The class discovers that while the client's markets are all very different, each company's motivation for product redesign can also be distinct, including competition, quality, cost, and marketability.

We did not encourage the management and engineering students to focus on the problems within their own disciplines. In fact, when asked to describe the content of their thesis topics, the engineering students felt that (on average) $35 \%$ of their efforts dealt with traditionally managerial issues. The management students considered $25 \%$ of their efforts to be in technical areas. While we have not directly compared these data to a control group, we feel that we have provided a genuinely interdisciplinary experience for the students.

One byproduct of the interdisciplinary experience for the students is their exposure to a variety of different kinds of professional work activities. We found that the students tended to reflect their project experiences onto their own career expectations. In many ways they seemed to be using the projects to evaluate what they wanted to do professionally. We believe that as a parallel activity to the students' job searches, the course serves an important career planning role.

Since many products require over one million hours of development activity, it is very difficult to expose students to a realistic design project. The redesign focus of our course appears to address this problem quite well. Whereas the students do not have the opportunity to generate the initial design configuration for the product, they do generate and evaluate many alternative approaches to product and process redesign. They are exposed to many product life cycle issues in design, such as reliability, field failures, and manufacturing costs. Such issues rarely surface in most design projects courses because the projects typically begin with a broadly stated problem and end at the conceptual design stage.

An important dimension of our experience in teaching this course has been the way in which it has drawn us towards research questions of industrial relevance. For example, time after time in the class projects, we have observed deficiencies in the way that firms compute manufacturing costs of a product. This information is critical to the redesign effort and yet is often poorly 
understood. This observation has led us to embark on a research effort to devise better design and manufacturing cost accounting schemes.

\section{Appendix Logistics}

In planning and executing this course, we have developed a few heuristics which may be of interest to others considering teaching a class like ours. We found that the overall effort to manage this course exceeds that required by one following the traditional lecture and examination format. Flowers [1987] suggests that universities must provide incentives for this type of teaching activity.

\section{Finding Industrial Sponsors and Products}

- Use local firms that are close enough for the students to visit. Most firms like to have some exposure on the campus.

- Each client company should identify an enthusiastic, well connected individual to serve as the main contact for the students.

- Do not guarantee to the sponsors specific deliverable results; only promise fresh ideas and written reports from the students.

- The products should have a number of components, subassemblies, or manufacturing operations for the students to focus on individually.

- The products should have a fairly long demand cycle, so that the students suggestions have a chance of eventually being adopted.

- Searching for good sponsors and projects can be very time consuming. Begin this process well before the academic year commences.

\section{Organizing the Student Projects}

- Three to five students per product team seems to work well. Try to balance the available skills and experiences among the groups.

- Since these projects require regular (indirect) supervision throughout the academic year, limit the enrollment to the number of students the faculty are willing to advise.

- Enforce definite transitions from problem definition to solution finding and implementation modes. 


\section{Motivating Student Groups}

- In class, discuss the documented strengths and weaknesses of group behavior, using product development teams as an example. [Ancona and Caldwell 1987]

- Schedule formal presentations for design review. Invite a panel of experts, whose presence will force students to discuss the broad issues.

- Encourage students to interact with their clients as professional consultants would.

\section{References}

Allen, T.J., Managing the Flow of Technology, The MIT Press, Cambridge, Massachusetts, 1977.

Ancona, D.G. and D.F. Caldwell, "Management Issues Facing New-Product Teams in High-Technology Companies", Advances in Industrial and Labor Relations, Vol. 4, 1987.

Barr, V., "The Proper Training for Innovation and Teamwork," Mechanical Engineering, January 1989.

Clark, K.B., W.B. Chew, and T. Fujimoto, "Product Development in the World Auto Industry: Strategy, Organization, and Performance," Working Paper, Harvard University Graduate School of Business Administration, 1987.

Flowers, W.C., "On Engineering Students' Creativity and Academia," 1987 ASEE Annual Conference Proceedings.

Jacobson, G. and J. Hillkirk, Xerox, American Samurai, Macmillan Publishing Company, New York, 1986.

Rabins, M.J., et al, Goals and Priorities for Research in Engineering Design, $A$ Report to the Design Research Community, American Society of Mechanical Engineers, July 1986. 